\title{
Comparison of Coupled and Uncoupled Currents during Glutamate Uptake by GLT-1 Transporters
}

\author{
Dwight E. Bergles, Anastassios V. Tzingounis, and Craig E. Jahr \\ Vollum Institute, Oregon Health and Science University, Portland, Oregon 97201-3098
}

The transport of glutamate across the plasma membrane is coupled to the movement of cations $\left(\mathrm{Na}^{+}, \mathrm{K}^{+}\right.$, and $\left.\mathrm{H}^{+}\right)$that are necessary for glutamate uptake and transporter cycling as well as anions that are uncoupled from the flux of glutamate. Although the relationship between these coupled (stoichiometric) and uncoupled (anion) transporter currents is poorly understood, transporter-associated anion currents often are used to monitor transporter activity. To define the kinetic relationship between these two components, we have recorded transporter currents associated with stoichiometric and anion charge movements occurring in response to the rapid application of L-glutamate to outside-out patches from human embryonic kidney cells expressing GLT-1 transporters. Transporterassociated anion currents were approximately twice as slow to

Glutamate transporters support the movement of glutamate across cell membranes. In the CNS this transport is necessary to remove the glutamate that is released during excitatory synaptic transmission, because glutamate is not subject to extracellular enzymatic degradation. The movement of glutamate into cells against a concentration gradient is achieved by harnessing energy stored in the electrochemical gradients for $\mathrm{Na}^{+}, \mathrm{K}^{+}$, and $\mathrm{H}^{+}$; the translocation of each molecule of glutamate is accompanied by the inward movement of $3 \mathrm{Na}^{+}$and $1 \mathrm{H}^{+}$and the outward movement of $1 \mathrm{~K}^{+}$(Zerangue and Kavanaugh, 1996; Levy et al., 1998), an unbalanced movement of charge that results in an inward current. In addition to this movement of coupled charges, glutamate transporters allow certain anions to flow across the membrane uncoupled from the movement of glutamate (Fairman et al., 1995; Wadiche et al., 1995a; Eliasof and Jahr, 1996). Because many more anions than coupled charges traverse the membrane during each cycle of transport, this feature has been exploited to resolve transporter currents in outside-out patches in which the density of transporters is too low to resolve reliably the currents mediated by the movement of coupled charges (Bergles and Jahr, 1997; Otis et al., 1997; Otis and Jahr, 1998; Wadiche and Kavanaugh, 1998; Mennerick et al., 1999). By combining outside-

Received Aug. 8, 2002; revised Sept. 17, 2002; accepted Sept. 19, 2002.

This work was supported by grants from the National Institutes of Health (NS21419 and NS40056 to C.E.J.), the Human Frontier Science Program (RG 119/2000 to C.E.J.), and the ALS Association (to D.E.B.). We thank Dr. Keiko Shimamoto for supplying TBOA, Dr. John Dunlop and Wyeth-Ayerst Research for providing the GLT-1-expressing cell line, and Drs. Michael Kavanaugh and Jacques Wadiche for valuable discussions throughout this project.

Correspondence should be addressed to Craig Jahr, Vollum Institute, Oregon Health and Science University, L474, 3181 South West Sam Jackson Park Road, Portland, OR 97201-3098. E-mail: jahr@ohsu.edu.

D. E. Bergles' present address: Department of Neuroscience, Johns Hopkins University School of Medicine, 725 North Wolfe Street, WBSB 813, Baltimore, MD 21205.

Copyright (C) 2002 Society for Neuroscience $\quad 0270-6474 / 02 / 2210153-10 \$ 15.00 / 0$ rise and decay as stoichiometric transport currents, but the presence of permeant anions did not slow transporter cycling. A kinetic model for GLT-1 was developed to simulate the behavior of both components of the transporter current and to estimate the capture efficiency of GLT-1. In this model the $\mathrm{K}^{+}$ counter-transport step was defined as rate-limiting, consistent with the slowing of transporter cycling after the substitution of internal $\mathrm{K}^{+}$with $\mathrm{Cs}^{+}$or $\mathrm{Na}^{+}$. The model predicts that in physiological conditions $\sim 35 \%$ of GLT-1 transporters function as buffers, releasing glutamate back into the extracellular space after binding.

Key words: glutamate transporter; GLT-1; EAAT2; uptake; astrocyte; patch clamp

out patch recording with rapid solution exchange techniques, we and others have found that it is possible to record charge movements associated with discrete steps in the transport cycle, revealing the speed at which glutamate and ion binding occur and conformational changes in the protein are induced. However, relating anion-potentiated transporter currents to the movement of glutamate relies on detailed knowledge about the relationship between the movement of coupled and uncoupled charges during transport.

The flux of both anions and substrate appear to be catalyzed by the transporter itself, because both components are present when transporters are expressed heterologously. Nevertheless, although the binding of glutamate activates the anion conductance, accumulation of substrate is neither dependent on anions nor affected by the direction of anion flux (Wadiche et al., 1995a). Furthermore, like many other neurotransmitter transporters (Sonders and Amara, 1996), glutamate transporters allow anions to traverse the membrane in the absence of substrate (Bergles and Jahr, 1997; Wadiche and Kavanaugh, 1998). Once bound by glutamate, the two pathways for charge transfer appear closely coupled as both currents rise to a peak rapidly and decay to a steady-state level in the continued presence of substrate (Bergles and Jahr, 1997; Grewer et al., 2000; Otis and Kavanaugh, 2000). However, the relative kinetics of these two currents vary between transporters (Bergles and Jahr, 1997; Auger and Attwell, 2000; Grewer et al., 2000), consistent with the differences in anion permeability (Wadiche et al., 1995a) and unitary conductance (Larsson et al., 1996; Wadiche and Kavanaugh, 1998) between transporters.

GLT-1 transporters are responsible for the majority of glutamate uptake in the mammalian brain (Rothstein et al., 1996; Tanaka et al., 1997). To determine the relationship between the movement of anions and coupled charges through GLT-1 during 
glutamate transport, we measured the kinetics of glutamateinduced anion and coupled transporter currents in outside-out patches removed from human embryonic kidney (HEK) cells that expressed a high density of GLT-1 transporters.

\section{MATERIALS AND METHODS}

Cell culture. GLT-1 transporters were expressed heterologously in HEK 293 cells. We used a stably transfected inducible cell line in which expression of GLT-1 was controlled by the ecdysone promoter (Dunlop et al., 1999). Cells were maintained in DMEM with $10 \%$ fetal calf serum, $0.4 \mathrm{mg} / \mathrm{ml}$ G418 (Invitrogen, San Diego, CA), $0.4 \mathrm{mg} / \mathrm{ml}$ Zeocin (Invitrogen), and $1 \%$ penicillin/streptomycin (Invitrogen) in tissue culture flasks at $37^{\circ} \mathrm{C}$ with $5 \% \mathrm{CO}_{2}$. To prepare cells for experiments, we plated them at a low density on glass coverslips coated with poly-L-lysine and collagen (Invitrogen), allowed them to grow for $1 \mathrm{~d}$, and then exposed them to 10 $\mu \mathrm{M}$ ponasterone A (Invitrogen) for $18-24 \mathrm{hr}$ before recording.

Outside-out patch recordings. Coverslips were transferred to a Plexiglas chamber mounted on a Zeiss FS1 fixed stage upright microscope equipped with differential interference contrast optics. Cells were superfused with artificial CSF (ACSF) consisting of (in mM): $160 \mathrm{NaCl}, 2.5$ $\mathrm{KCl}, 2.5 \mathrm{CaCl}_{2}, 1.3 \mathrm{MgCl}, 10 \mathrm{HEPES}$, and 10 glucose, $\mathrm{pH} 7.2(\mathrm{NaOH})$, 330 mOsm. Whole-cell recordings were made from HEK cells with the use of established techniques, using internal solutions of the following composition (in mM): $160 \mathrm{KA}^{-}$(where $\mathrm{A}^{-}$corresponds to the anions gluconate, nitrate, or thiocyanate), 10 EGTA, $10 \mathrm{HEPES}$, and $1 \mathrm{MgCl}_{2}$, $\mathrm{pH}$ 7.3. TEA $(20 \mathrm{~mm})$ was substituted for K-gluconate for the paired pulse recovery experiments shown in Figure 4 to reduce the noise associated with $\mathrm{K}^{+}$channel gating. Holding potentials have been corrected for the different junction potentials of the internal solutions. Patch electrodes had resistances of 1.5-3 $\mathrm{M} \Omega$ when filled with the internal solution. After the establishment of whole-cell configuration the pipette was pulled away slowly from the cell, resulting in the removal of a patch of membrane in the outside-out configuration. Patches were brought in front of a multibarreled glass flow pipe that had control and test solutions flowing out. The standard patch ACSF solution contained (in $\mathrm{mM}$ ): 170 $\mathrm{NaCl}, 2.5 \mathrm{KCl}, 2.5 \mathrm{CaCl}_{2}, 1.3 \mathrm{MgCl}_{2}$, and 10 HEPES, pH $7.2(\mathrm{NaOH})$, $330 \mathrm{mOsm}$. All solutions were made by using HPLC grade water and ultrapure salts. Reagents (agonists, antagonists, etc.) were added directly to this solution. Rapid exchange of the solution at the patch was achieved via the use of a piezoelectric bimorph (Tong and Jahr, 1994). Exchange times of $<200 \mu \mathrm{sec}(10-90 \%)$ were measured at the end of each recording by recording the junction current produced at the tip of the electrode by switching between solutions of different ionic strength. These "open tip" responses are displayed above each trace to indicate the duration of agonist/antagonist application. All responses were recorded at room temperature $\left(22-24^{\circ} \mathrm{C}\right)$ at a membrane potential of $-90 \mathrm{mV}$, unless otherwise noted. A range of glutamate concentrations was applied to patches by connecting a miniature manifold (Warner Instruments, Grand Haven, MI) to one barrel of the flow pipe.

Patch currents were recorded with an Axopatch 200A amplifier (Axon Instruments, Foster City, CA), filtered at $5 \mathrm{kHz}$, and digitized at $50 \mathrm{kHz}$ by using programs written in Axobasic (Axon Instruments). Analysis was performed by using programs written in Axobasic or Origin (Microcal, Northampton, MA) software. Data are represented as \pm SEM, unless otherwise noted. Rise time was calculated from 20 to $80 \%$ of the peak, and half-decay was measured from the peak to the steady-state level. Significance was measured with a Student's $t$ test, and significance reflects a $p$ value of $<0.05$. Sweeps are averages of 5-30 responses.

Modeling. A chemical-kinetic model of glutamate transport was constructed in the Simulation Control Program environment (Simulation Resources, Redlands, CA) to describe the behavior of GLT-1. This cyclical model incorporates the discrete binding of $3 \mathrm{Na}^{+}, \mathrm{H}^{+}$, glutamate, and $\mathrm{K}^{+}$, as required by the known stoichiometry of transport (Zerangue and Kavanaugh, 1996), anion conducting states, and voltagedependent transitions. The binding order of $\mathrm{Na}^{+}$and glutamate incorporates the finding that at least one $\mathrm{Na}^{+}$binds before glutamate and at least one $\mathrm{Na}^{+}$binds after glutamate (Wadiche et al., 1995a; Watzke et al., 2001). We also place $\mathrm{H}^{+}$translocation with glutamate and $\mathrm{Na}^{+}$ (Zerangue and Kavanaugh, 1996) as opposed to with the $\mathrm{K}^{+}$translocation step (Auger and Attwell, 2000), because cysteine is transported as a neutral zwitterion (A. Tzingounis, personal communication). We have chosen to make the $\mathrm{K}^{+}$translocation step rate-limiting, based on the work of Kanner (Kanner and Sharon, 1978; Kanner and Bendahan, 1982) and because of the dramatic slowing of the cycle when $\mathrm{Cs}^{+}$or $\mathrm{Na}^{+}$is
A

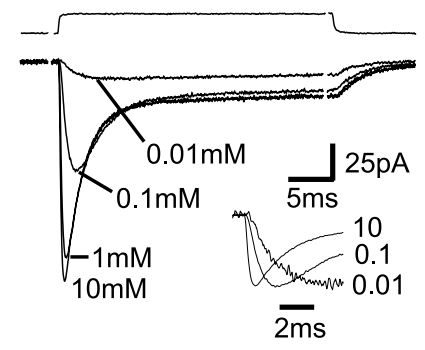

B

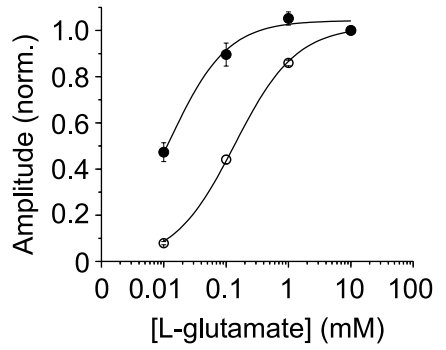

Figure 1. Characteristics of GLT-1 transporter currents in outside-out patches. $A$, Response of an outside-out patch removed from a HEK cell expressing GLT-1 to a range of L-glutamate concentrations. Inset, The peak responses to 0.01 and $0.1 \mathrm{~mm}$ L-glutamate have been scaled to the peak of the response to $10 \mathrm{~mm}$ L-glutamate to illustrate the concentration dependence of the rise time of the transporter currents. $B$, L-Glutamate dose-response relationship of the peak (open circles) and the steady-state ( filled circles) amplitudes of GLT-1-mediated transporter currents. Data were fit with the logistic equation; KSCN-based internal solution.

substituted for internal $\mathrm{K}^{+}$(see Results). The rates of the $\mathrm{K}^{+}$translocation step were set by the paired pulse recovery times. Model parameters were adjusted to provide the best fit to a set of averaged transporter currents recorded under each of the conditions described. All simulations include all of the anion conducting states and, in addition, use the same rate constants except where rate changes are described explicitly in the text. Simulated transporter responses in the presence of permeant anions are in units of open probabilities; in the absence of anions, transporter responses are in units of amperes per single transporter.

\section{RESULTS}

\section{GLT-1 expression in HEK cells}

The charge movement initiated by the binding of glutamate to transporters is highly dependent on the species of ions present. Because of the presence of an associated anion conductance, transporter currents elicited by glutamate are much larger in the presence of chaotropic anions such as thiocyanate $\left(\mathrm{SCN}^{-}\right)$and nitrate $\left(\mathrm{NO}_{3}{ }^{-}\right)$(Fairman et al., 1995; Wadiche et al., 1995a; Eliasof and Jahr, 1996; Bergles and Jahr, 1997). Our initial experiments were performed in the presence of intracellular $\mathrm{SCN}^{-}$ to maximize the size of the glutamate transporter current. L-Glutamate (10 $\mathrm{mm}$ ) elicited large inward currents (peak amplitude, $-206.2 \pm 21.3 \mathrm{pA} ; n=20$ ) in patches from HEK 293 cells that were exposed to ponasterone $\mathrm{A}$ for $>24 \mathrm{hr}$ to induce the expression of GLT-1 (Fig. $1 A)$. In contrast, L-glutamate $(10 \mathrm{~mm})$ did not evoke currents in outside-out patches from cells that had not been exposed to ponasterone A $(n=5)$, indicating that the expression of endogenous glutamate transporters in this cell line was below the limit of detection of this technique (Dunlop et al., 1999). Glutamate transporter currents rose to a peak rapidly (20-80\% rise time, $248 \pm 10 \mu \mathrm{sec})$ and then decayed to a quasi-steady-state level in $1.7 \pm 0.1 \mathrm{msec}$ (half-decay time) in the continued presence of L-glutamate. With the removal of glutamate this current decayed to baseline with a biexponential decay $(\tau 1=1.4 \pm 0.11 \mathrm{msec}, 74 \% ; \tau 2=21.9 \pm 2.1 \mathrm{msec})$. The kinetics of these transporter currents were dependent on the concentration of L-glutamate, with the rise and decay kinetics slower with lower concentrations of L-glutamate (Fig. $1 A$ ). In addition, the $\mathrm{EC}_{50}$ of L-glutamate was much lower when measured at the peak of the response $(137.8 \pm 11.8 \mu \mathrm{M} ; n=9)$ than when measured at steady state $(12.4 \pm 2.5 \mu \mathrm{M})$ (Fig. $1 B)$. These glutamate-evoked transporter currents closely resembled glutamate transporter currents recorded in outside-out patches from astrocytes in hip- 
pocampal slices (Bergles and Jahr, 1997, 1998) and from HEK cells expressing EAAT2 transporters (Otis and Kavanaugh, 2000).

\section{A model for transport by GLT-1}

A chemical-kinetic model developed to account for the properties of the EAAT3 transporter (A. Tzingounis, personal communication) was adapted to simulate the kinetics of GLT-1-mediated transporter currents (Fig. 2A). This model is based on an alternating access scheme (Läuger, 1991; Kavanaugh, 1998) and incorporates the dependence of glutamate transport on $\mathrm{Na}^{+}, \mathrm{K}^{+}$, and $\mathrm{H}^{+}$as well as transmembrane voltage. The permeability to anions, in physiological conditions, is accounted for primarily by anion conducting states directly connected to three states in the cycle: $\mathrm{T}_{\mathrm{o}} \mathrm{Na}_{2} \mathrm{H}, \mathrm{T}_{\mathrm{o}} \mathrm{Na}_{3} \mathrm{GH}$, and $\mathrm{T}_{\mathrm{i}} \mathrm{K}$ (although very minor components of the conductance were from open states connected to the other $\mathrm{Na}^{+}$-bound external states) (Fig. $2 \mathrm{~B}$ ). In the absence of substrate, glutamate transporters exhibit a "leak" conductance to anions that is shut off by antagonists such as kainate, dihydrokainate (Bergles and Jahr, 1997; Otis and Jahr, 1998), and D,Lthreo- $\beta$-benzyloxyaspartate (TBOA) (see below; Watzke et al., 2001). This standing leak conductance is accounted for by the open state connected to $\mathrm{T}_{\mathrm{o}} \mathrm{Na}_{2} \mathrm{H}$ (in addition to a very small component added via $\mathrm{T}_{\mathrm{o}} \mathrm{Na}_{2}$ ). With the rapid application of substrate (10 mM L-glutamate) to the external face of the transporter, a fast transient anion current is evoked, primarily from the occupancy of the open state attached to $\mathrm{T}_{\mathrm{o}} \mathrm{Na}_{3} \mathrm{GH}$. After several milliseconds a steady-state current is reached that is a combination of occupation of the open states attached to $\mathrm{T}_{\mathrm{i}} \mathrm{K}$ and $\mathrm{T}_{\mathrm{o}} \mathrm{Na}_{3} \mathrm{GH}$; the open state attached to $\mathrm{T}_{\mathrm{o}} \mathrm{Na}_{2} \mathrm{H}$, the main leak conductance, is practically unoccupied during the presence of substrate. At the end of the pulse of substrate the slow return to the leak conductance level is the result of the relatively slow deoccupation of $\mathrm{T}_{\mathrm{i}} \mathrm{K}$ because of the rate-limiting, potassiumdependent translocation step. Were it not for the $\mathrm{T}_{\mathrm{i}} \mathrm{K}$ open state, an apparent outward current, relative to the resting leak, is produced at the end of the substrate application. This outward current is actually the result of a decreased occupancy of all anion conductance states, below that observed at rest. Such a current is seen in patch recordings from hippocampal astrocytes (Bergles and Jahr, 1997) and Purkinje cells (Otis and Jahr, 1998); however, it was not observed in EAAT2 (Otis and Kavanaugh, 2000) or in the current study of GLT-1. The lack of this "overshooting" decrease in anion conductance requires a compensating open state that precedes the rate-limiting step, which in the present model is served by the $\mathrm{T}_{\mathrm{i}} \mathrm{K}$ open state. As shown in Figure $2 C$, this model mimics the peak and steady-state dose-response curves of the anion currents through GLT-1 (Fig. 1).

\section{Comparison of coupled versus uncoupled transporter currents}

To determine the relationship between the anion current associated with glutamate transport (Fairman et al., 1995; Wadiche et al., 1995a) and the current produced by the movement of charges stoichiometrically linked to transport, we recorded glutamate transporter currents in the absence of permeant anions in the intracellular solution. Transporter currents recorded with internal gluconate $\left(\mathrm{K}^{+}\right.$salt), which does not permeate the transporterassociated anion channel (Wadiche et al., 1995a; Eliasof and Jahr, 1996; Wadiche and Kavanaugh, 1998), were smaller (peak amplitude, $-28.5 \pm 2.0 \mathrm{pA} ; n=16$ ) and exhibited faster kinetics (rise time, $138 \pm 8 \mu \mathrm{sec}$; half-decay time, $860 \pm 41 \mu \mathrm{sec}$ ) than currents

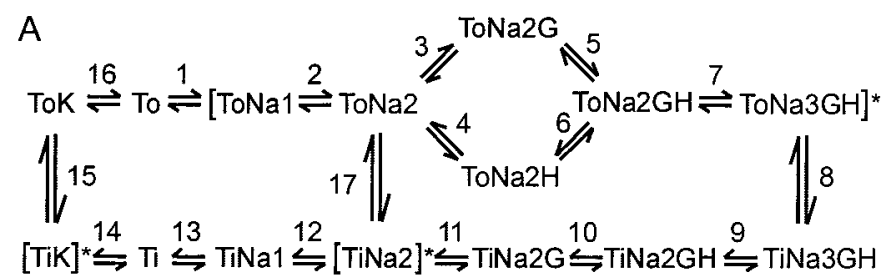

$\begin{array}{lcrrrr} & \text { Forward } & \text { Backward } & & \text { Forward } & \text { Backward } \\ 1 & 1 \times 10^{4} \mathrm{M}^{-1} \mathrm{~s}^{-1} & 1 \times 10^{2} \mathrm{~s}^{-1} & 10 & 3000 \mathrm{~s}^{-1} & 9 \times 10^{10} \mathrm{M}^{-1} \mathrm{~s}^{-1} \\ 2 & 1 \times 10^{4} \mathrm{M}^{-1} \mathrm{~s}^{-1} & 5 \times 10^{2} \mathrm{~s}^{-1} & 11 & 3000 \mathrm{~s}^{-1} & 1 \times 10^{5} \mathrm{M}^{-1} \mathrm{~s}^{-1} \\ 3 & 6 \times 10^{6} \mathrm{M}^{-1} \mathrm{~s}^{-1} & 500 \mathrm{~s}^{-1} & 12 & 1 \times 10^{5} \mathrm{~s}^{-1} & 2 \times 10^{7} \mathrm{M}^{-1} \mathrm{~s}^{-1} \\ 4 & 6 \times 10^{11} \mathrm{M}^{-1} \mathrm{~s}^{-1} & 700 \mathrm{~s}^{-1} & 13 & 1 \times 10^{5} \mathrm{~s}^{-1} & 1 \times 10^{8} \mathrm{M}^{-1} \mathrm{~s}^{-1} \\ 5 & 6 \times 10^{11} \mathrm{M}^{-1} \mathrm{~s}^{-1} & 700 \mathrm{~s}^{-1} & 14 & 1 \times 10^{6} \mathrm{M}^{-1} \mathrm{~s}^{-1} & 1000 \mathrm{~s}^{-1} \\ 6 & 6 \times 10^{6} \mathrm{M}^{-1} \mathrm{~s}^{-1} & 500 \mathrm{~s}^{-1} & 15 & 40 \mathrm{~s}^{-1} & 10 \mathrm{~s}^{-1} \\ 7 & 1 \times 10^{4} \mathrm{M}^{-1} \mathrm{~s}^{-1} & 1 \times 10^{3} \mathrm{~s}^{-1} & 16 & 2 \times 10^{4} \mathrm{~s}^{-1} & 1 \times 10^{6} \mathrm{M}^{-1} \mathrm{~s}^{-1} \\ 8 & 2000 \mathrm{~s}^{-1} & 1900 \mathrm{~s}^{-1} & 17 & 1.4 \mathrm{~s}^{-1} & 0.01 \mathrm{~s}^{-1} \\ 9 & 1000 \mathrm{~s}^{-1} & 4 \times 10^{4} \mathrm{M}^{-1} \mathrm{~s}^{-1} & & & \end{array}$
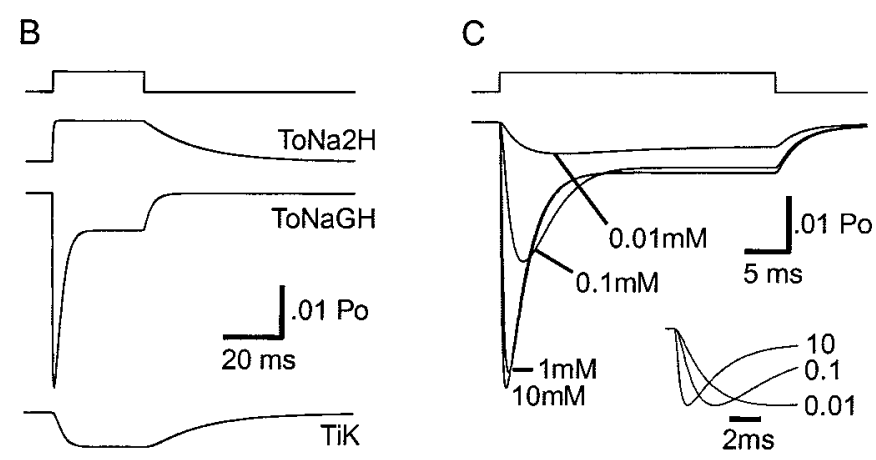

Figure 2. Kinetic model of the GLT-1 transporter. $A$, Illustration of the discrete states and transition rates present in the model. Four transitions are voltage-dependent: $\mathrm{T}_{\mathrm{o}} \mathrm{Na}_{2} \mathrm{GH}$ to $\mathrm{T}_{\mathrm{o}} \mathrm{Na}_{3} \mathrm{GH}(z \delta=0.55), \mathrm{T}_{\mathrm{i}} \mathrm{Na}_{3} \mathrm{GH}$ to $\mathrm{T}_{\mathrm{i}} \mathrm{Na}_{2} \mathrm{GH}(z \delta=0.4$, asymmetry of 0.1$), \mathrm{T}_{\mathrm{i}} \mathrm{K}$ to $\mathrm{T}_{\mathrm{o}} \mathrm{K}(z \delta=0.59$, asymmetry of 0.9$)$, and $\mathrm{T}_{\mathrm{o}}$ to $\mathrm{T}_{\mathrm{o}} \mathrm{Na}_{1}(z \delta=0.46)$. Anion conducting states (data not shown) are attached to the following states: $\mathrm{T}_{\mathrm{o}} \mathrm{Na}_{1}, \mathrm{~T}_{\mathrm{o}} \mathrm{Na}_{2}, \mathrm{~T}_{\mathrm{o}} \mathrm{Na}_{2} \mathrm{G}$, $\mathrm{T}_{\mathrm{o}} \mathrm{Na}_{2} \mathrm{H}, \mathrm{T}_{\mathrm{o}} \mathrm{Na}_{2} \mathrm{GH}$ (all with opening rates of $50 / \mathrm{sec}$ and closing rates of $4700 / \mathrm{sec}$ ), $\mathrm{T}_{\mathrm{o}} \mathrm{Na}_{3} \mathrm{GH}$ (opening rate, $1500 / \mathrm{sec}$; closing rate, 10,000/sec), $\mathrm{T}_{\mathrm{i}} \mathrm{Na}_{2}$ (opening rate, $80 / \mathrm{sec}$; closing rate, $4700 / \mathrm{sec}$ ), and $\mathrm{T}_{\mathrm{i}} \mathrm{K}$ (opening rate, $55 / \mathrm{sec}$; closing rate, $4700 / \mathrm{sec})$. Simulated anion conductances are the sum of all of these states. The numbers in the columns correspond to the rates for the transitions noted in the model. $B$, Occupancies of the three states that are the main contributors to the anion conductance in control conditions in response to a $30 \mathrm{msec}$ application of $10 \mathrm{mM}$ L-glutamate. A downward deflection indicates increased occupancy of the state. $C$, Simulated dose-response of the anion conductance for $0.01-10 \mathrm{~mm}$ L-glutamate (sum of all anion conducting states). Inset, Simulated peak responses to 0.01 and $0.1 \mathrm{~mm}$ glutamate have been scaled to the peak response of $10 \mathrm{~mm}$ glutamate.

recorded with the permeant anion thiocyanate (Fig. 3A,B). However, the shape of the responses was similar under the two conditions, with the stoichiometric current rising to a peak, decaying to a steady-state level in the continued presence of glutamate, and returning to baseline with a biexponential decay with the removal of glutamate. The ratio of the amplitude measured at steady state to that measured at the peak was similar for both 


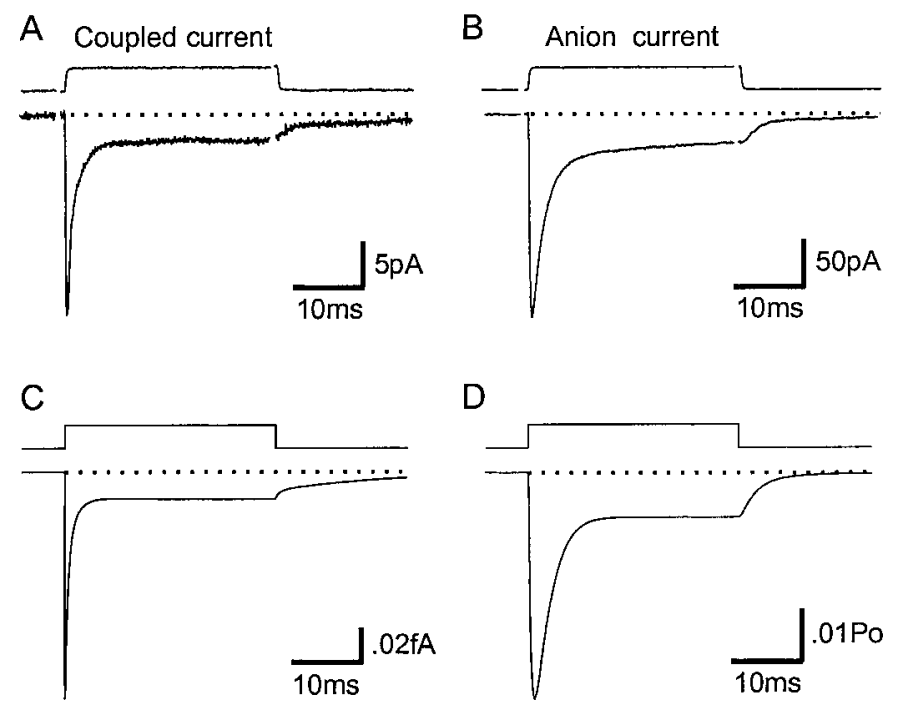

Figure 3. Comparison of coupled and uncoupled responses elicited by L-glutamate. $A$, L-Glutamate-evoked $(10 \mathrm{mM})$ transporter current from an outside-out patch recorded in the absence of permeant anions (Kgluconate-based internal solution). $B$, L-Glutamate-evoked (10 mM) transporter current from an outside-out patch recorded in the presence of permeant anions (KSCN-based internal solution). $C$, Simulation of the GLT-1 model in response to $10 \mathrm{~mm}$ L-glutamate in the absence of permeant anions (plot of charge transfer vs time for a single transporter). $D$, Simulation result of the GLT-1 model in response to $10 \mathrm{~mm}$ L-glutamate in the presence of permeant anions.

anion and stoichiometric currents (SS/peak ratio: KSCN, $0.10 \pm$ $0.01, n=20$; K-gluconate, $0.15 \pm 0.01, n=16$ ).

The stoichiometric current is accounted for in the model (Fig. $3 C$ ) by the net flux of transporters through the voltage-dependent steps of $\mathrm{Na}^{+}$binding to two external states $\left(\mathrm{T}_{\mathrm{o}}\right.$ and $\left.\mathrm{T}_{\mathrm{o}} \mathrm{Na}_{2} \mathrm{GH}\right)$, $\mathrm{Na}^{+}$unbinding from the cytoplasmic face $\left(\mathrm{T}_{\mathrm{i}} \mathrm{Na}_{3} \mathrm{GH}\right)$, and from the return potassium-dependent translocation step $\left(\mathrm{T}_{\mathrm{i}} \mathrm{K}\right.$ to $\left.\mathrm{T}_{\mathrm{o}} \mathrm{K}\right)$. The forward translocation step $\left(\mathrm{T}_{\mathrm{o}} \mathrm{Na}_{3} \mathrm{GH}\right.$ to $\left.\mathrm{T}_{\mathrm{i}} \mathrm{Na}_{3} \mathrm{GH}\right)$ is modeled as a voltage-independent transition and thus does not participate in the stoichiometric current. The voltage dependence and the rationale for these assumptions are addressed below.

The slower kinetics of the transporter currents recorded with internal $\mathrm{SCN}^{-}$may indicate that conformational changes associated with charge transfer and anion channel gating were slowed in the presence of this anion. To address this question, we compared the time necessary for the peak amplitude of the response to recover from the steady-state level (paired pulse recovery) in recordings with gluconate as the primary internal anion (Fig. $4 B$ ) with recordings in which $\mathrm{SCN}^{-}$was the primary internal anion (Fig. 4A). The time constant of recovery was not significantly different for the two conditions $\left(\tau_{\mathrm{KSCN}}=33.1 \pm 0.55 \mathrm{msec}, n=\right.$ $\left.6 ; \tau_{\text {gluconate }}=32.5 \pm 0.7 \mathrm{msec}, n=10\right)$ (Fig. $4 C$ ), indicating that internal thiocyanate does not slow down the cycling rate of GLT-1 significantly. The model faithfully reproduces the paired pulse recovery times in both conditions (Fig. 5). Because the recovery times were slower than those recorded in patches from astrocytes (Bergles and Jahr, 1997) that express both GLT-1 and GLAST, we reassessed the recovery times in the present study by using a $\mathrm{SCN}^{-}$-based internal solution more similar to that used in the previous study (i.e., without TEA). In the absence of TEA, recovery was speeded by $\sim 35 \%\left(\tau_{\mathrm{KSCN}-\mathrm{TEA}}=21.8 \pm 0.8 \mathrm{msec}\right.$; $n=10$ ) (Fig. $4 C$, open squares), suggesting that TEA slowed the rate-limiting steps of the cycle. Such a slowing was mimicked in
A

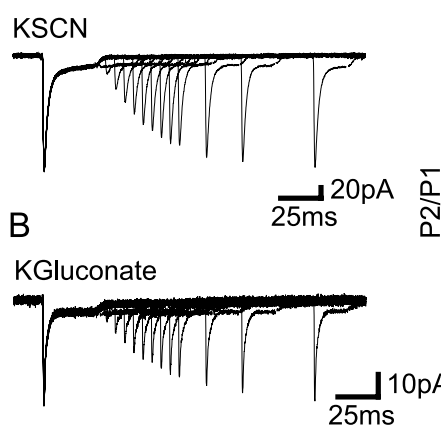

C

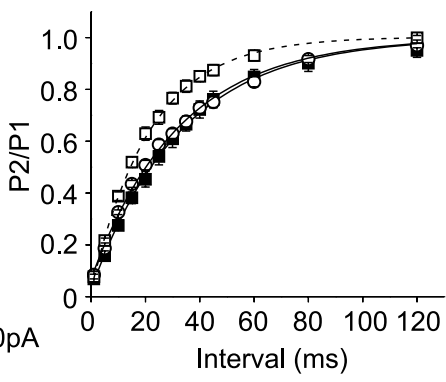

Figure 4. The paired pulse recovery rate of GLT-1 transporters is not affected by the presence of permeant anions. $A$, Response of a patch to pairs of applications of $10 \mathrm{~mm}$ L-glutamate (KSCN-based internal solution). The interval between control (30 msec duration) and test $(20 \mathrm{msec}$ duration) applications was $1-120$ msec. $B$, Response of a patch to paired applications of $10 \mathrm{~mm}$ L-glutamate recorded without permeant anions in the internal solution (K-gluconate-based internal solution). $C$, Plot of the ratio of the peak amplitude of the second $(P 2)$ to the first $(P 1)$ response to paired applications of $10 \mathrm{~mm}$ L-glutamate recorded with ( filled squares) and without anions (open circles) in the internal solution (solid lines are single exponential fits to the data). Removal of TEA-Cl (10 mM) from the internal solution (open squares) speeded the decay by $\sim 35 \%$ (dashed line).

A

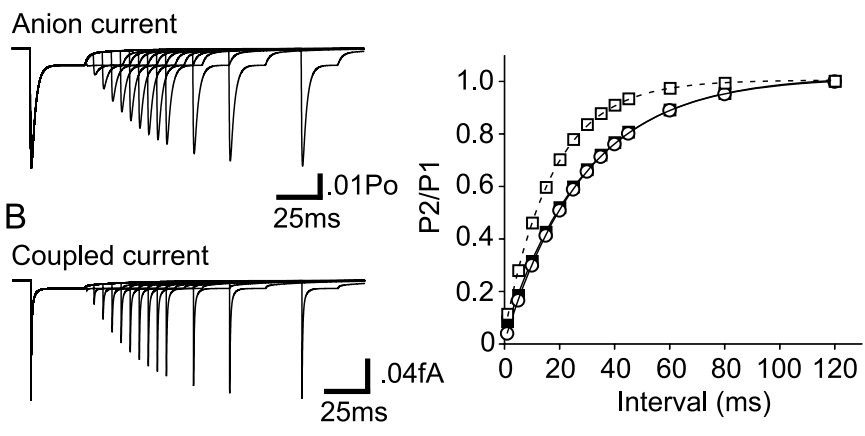

Figure 5. Simulations of the paired pulse recovery rate of GLT-1 transporters. $A$, Simulated uncoupled (anion conductance) responses of a patch to paired applications of $10 \mathrm{~mm} \mathrm{L-glutamate}$. The protocol is the same as in Figure 4. B, Simulated coupled responses of a patch to paired applications of $10 \mathrm{~mm} \mathrm{~L}$-glutamate. $C$, Plot of the ratio of the peak amplitude of the second $(P 2)$ to the first $(P 1)$ response to paired applications of 10 mM L-glutamate recorded with ( filled squares) and without anions (open circles) in the internal solution (solid lines are single exponential fits to the data). The dashed line is a single exponential fit to the model adjusted to reflect the removal of TEA-Cl (open squares; see Results).

the model by slowing the binding rate of internal $\mathrm{K}^{+}$from $10^{6}$ to $10^{4}$ per $\mathrm{M} / \mathrm{sec}$ and increasing the opening rate from $\mathrm{T}_{\mathrm{i}} \mathrm{K}$ from 55 to $100 / \mathrm{sec}\left(\tau_{\text {anion }+\mathrm{TEA}}=29.9 \pm 0.4 \mathrm{msec} ; \tau_{\text {stoichiometric }}=29.0 \pm\right.$ $0.1 \mathrm{msec} ; \tau_{\text {anion-TEA }}=17.6 \pm 0.2 \mathrm{msec}$ ) (Fig. 5). These data suggest that TEA interferes with the binding of $\mathrm{K}^{+}$to the internal face of the transporter, as has been reported for the $\mathrm{Na}^{+} / \mathrm{K}^{+}$pump (Eckstein-Ludwig et al., 1998). With the exception of these experiments, TEA was not included in internal solutions used in this study. The model predicts that the anion current $\left(\mathrm{SCN}^{-}\right)$has slower kinetics than the stoichiometric current (gluconate) because the open state linked to $\mathrm{T}_{\mathrm{o}} \mathrm{Na}_{3} \mathrm{GH}$ is reached after $\mathrm{Na}^{+}$binds within the membrane field (to $\mathrm{T}_{\mathrm{o}} \mathrm{Na}_{2} \mathrm{GH}$ ), and this open state is revisited several times, on average, before glutamate unbinds. In the absence of internal TEA, $\mathrm{Na}^{+}$, or glutamate, the model predicts that the cycling rate 
of GLT-1 is $44 / \mathrm{sec}$, whereas the paired pulse recovery requires $17.6 \mathrm{msec}$ (a rate of $57 / \mathrm{sec}$ ). The paired pulse recovery rate is faster because some of the bound glutamate is not transported and released into the cytoplasm; instead, glutamate unbinds to the outside, providing a second pathway for recovery. In conditions that may mimic the astrocytic cytoplasm environment more accurately (10 $\mathrm{mm} \mathrm{Na}^{+}, 50 \mu \mathrm{M}$ glutamate inside; Chatton et al., 2000 ), the model predicts that the cycling rate will slow to $37 / \mathrm{sec}$ (and the paired pulse recovery to $51 / \mathrm{sec}$ ). Thus at physiological temperature, assuming a $\mathrm{Q}_{10}$ of $\sim 2-3$ (Bergles and Jahr, 1998; Wadiche and Kavanaugh, 1998), the cycling rate of GLT-1 transporters is likely to be $\sim 10-20 \mathrm{msec}$.

\section{Internal $\mathrm{Cs}^{+}$slows counter-transport}

Previous studies of transporter currents in isolated retinal Müller cells demonstrated that $\mathrm{Cs}^{+}$could substitute for $\mathrm{K}^{+}$at the counter-transport site to support glutamate transporter cycling; however, transporter currents elicited with $\mathrm{Cs}^{+}$in the pipette were only two-thirds as large as those elicited with $\mathrm{K}^{+}$in the pipette (Barbour and Attwell, 1991). To determine whether $\mathrm{Cs}^{+}$ also supports the cycling of GLT-1, we made a complete substitution of $\mathrm{K}^{+}$with $\mathrm{Cs}^{+}$in the internal solution and recorded transporter currents in response to $10 \mathrm{~mm}$ L-glutamate. Nitratebased $\left(\mathrm{NO}_{3}{ }^{-}\right)$internal solutions were used for these experiments because the $\mathrm{Cs}^{+}$salt of thiocyanate is not soluble at physiological $\mathrm{pH}$. The peak amplitude of the GLT-1 transporter current recorded with $\mathrm{Cs}^{+}$was significantly smaller than that recorded with $\mathrm{K}^{+}\left(\mathrm{CsNO}_{3}:-16.8 \pm 2.6 \mathrm{pA}, n=8 ; \mathrm{KNO}_{3}:-49.2 \pm 7.3 \mathrm{pA}, n=\right.$ $6 ; p<0.0001$ ) (Fig. 6A,B). In addition, the steady-state amplitude was reduced nearly to zero with internal $\mathrm{Cs}^{+}$, suggesting that cycling occurs much more slowly with this cation and that anion conducting states are visited infrequently. In support of this conclusion the peak of the transporter current recovered by only $47 \pm 5 \%(n=6)$ in $120 \mathrm{msec}$ in $\mathrm{Cs}^{+}$compared with $105 \pm 3 \%$ $(n=8)$ with $\mathrm{K}^{+}$. This is consistent with the effects of $\mathrm{Cs}^{+}$on the $\mathrm{Na}^{+} / \mathrm{K}^{+}$pump in which $\mathrm{Cs}^{+}$has a 20 -fold lower affinity than $\mathrm{K}^{+}$ (Omay and Schwarz, 1992).

Similar experiments were performed with K-gluconate and Cs-gluconate to determine whether the stoichiometric current exhibited a similar behavior after the replacement of internal $\mathrm{K}^{+}$ with $\mathrm{Cs}^{+}$. L-Glutamate-evoked transporter currents were smaller with Cs-gluconate $(-9.72 \pm 2.15 \mathrm{pA} ; n=6)$ than with K-gluconate $(-28.5 \pm 2.0 \mathrm{pA} ; n=16)$, they exhibited a smaller steady-state current, and they cycled more slowly (paired pulse recovery at $120 \mathrm{msec}$ : Cs-gluconate, $52 \pm 4 \%, n=4$; K-gluconate, $104 \pm 2 \%, n=4$ ) (Fig. $6 E, F)$, similar to the effects observed on the anion-potentiated transporter currents.

The effects of internal $\mathrm{Cs}^{+}$could be mimicked in the model by using modifications similar to those used to fit the data recorded with internal TEA. For internal $\mathrm{Cs}^{+}$the $\mathrm{K}^{+}$binding rate to $\mathrm{T}_{\mathrm{i}}$ was slowed to $8 \times 10^{3}$ per $\mathrm{M} / \mathrm{sec}$, the translocation rate from $\mathrm{T}_{\mathrm{i}} \mathrm{K}$ to $\mathrm{T}_{\mathrm{o}} \mathrm{K}$ was slowed from 40 to $8 / \mathrm{sec}$, and the opening rate from $\mathrm{T}_{\mathrm{i}} \mathrm{K}$ was increased from 55 to $85 / \mathrm{sec}$. These modifications were sufficient to mimic the kinetic changes of both anion and stoichiometric currents (Figs. $6 C, D, 7 C, D$ ). The model predicts that internal $\mathrm{Cs}^{+}$will slow the cycling rate to $\sim 6 / \mathrm{sec}$, over sevenfold slower than with internal $\mathrm{K}^{+}$. Because many physiological studies of synaptic transmission use internal $\mathrm{Cs}^{+}$to block $\mathrm{K}^{+}$channels and increase membrane resistance, this action of internal $\mathrm{Cs}^{+}$on transport could decrease neuronal uptake and alter the strength of synaptic excitation. One deficiency of the model is that it does not predict the more than twofold decrease in the peak of the
A

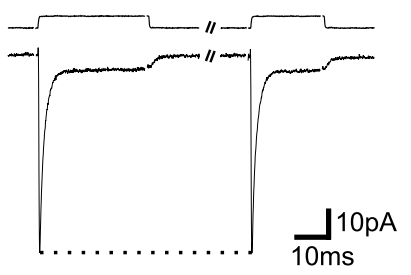

B

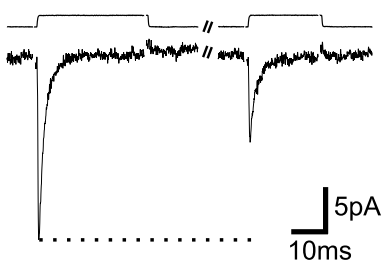

C

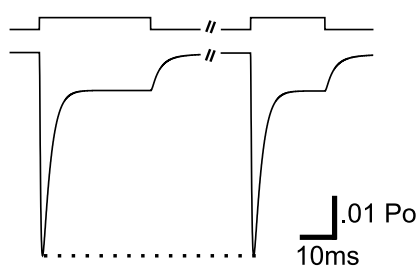

D

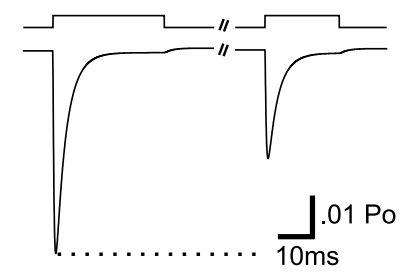

E

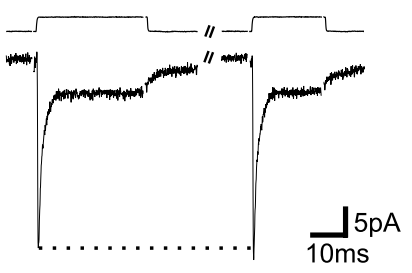

$\mathrm{F}$

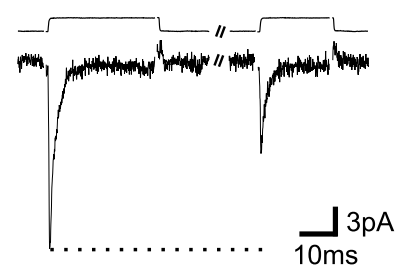

G

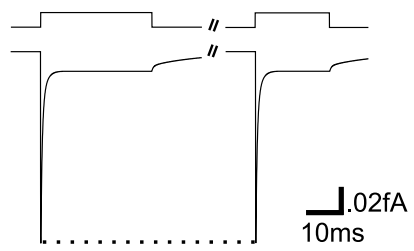

$\mathrm{H}$

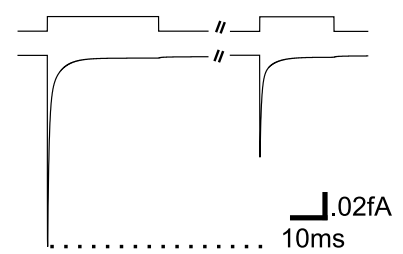

Figure 6. Internal $\mathrm{Cs}^{+}$slows the cycling rate of GLT-1 transporters. $A$, Response of a patch to paired applications of L-glutamate (10 mM) (interval, $120 \mathrm{msec}$ ); $\mathrm{KNO}_{3}$-based internal solution. $B$, Response of a patch to the paired application of L-glutamate $(10 \mathrm{~mm})$ as in $A$ but recorded with a $\mathrm{CsNO}_{3}$-based internal solution. $C$, Simulation of uncoupled conductance (anion current) as in $A$. $D$, Simulation of uncoupled conductance to reflect slower binding of $\mathrm{Cs}^{+}$as in $B$. E, Response of a patch to paired applications of L-glutamate $(10 \mathrm{~mm})$ separated by 120 msec recorded with a K-gluconate-based internal solution. $F$, Response of a patch to paired applications of L-glutamate $(10 \mathrm{mM})$ separated by 120 msec recorded with a Cs-gluconate-based internal solution. $G$, Simulations of the coupled current in $E$. $H$, Simulations of the coupled current adjusted to reflect the slower binding of $\mathrm{Cs}^{+}$as in $F$.

current seen with internal $\mathrm{Cs}^{+}$. This discrepancy could be accounted for if $\mathrm{Cs}^{+}$, in addition to its effect on the rate of counter-transport, acted as a noncompetitive antagonist, effectively decreasing the pool of available transporters and further diminishing the capacity of uptake.

\section{Internal $\mathrm{Na}^{+}$blocks counter-transport}

The dependence of counter-transport on intracellular $\mathrm{K}^{+}$(Kanner and Sharon, 1978; Kanner and Bendahan, 1982) suggested that removal of internal $\mathrm{K}^{+}$would prevent transporter cycling. Substitution of $\mathrm{Na}^{+}$for internal $\mathrm{K}^{+}$therefore could isolate the charge movements associated only with the $\mathrm{Na}^{+}$-bound transitions. To investigate this possibility, we replaced $\mathrm{K}^{+}$with $\mathrm{Na}^{+}$in the pipette solution (NaSCN). Transporter currents persisted under these conditions but had significantly smaller amplitudes 
A

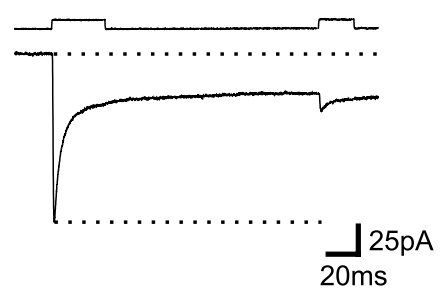

C

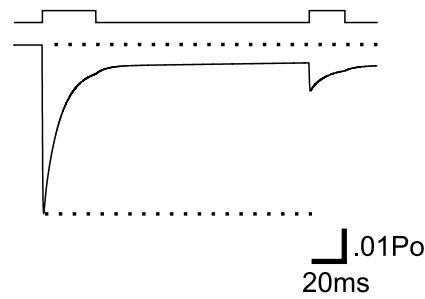

E

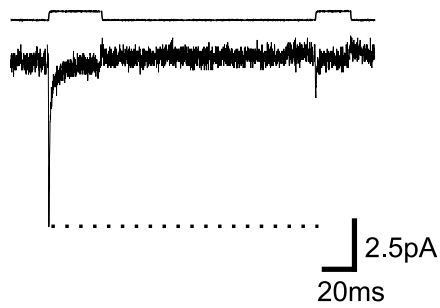

G

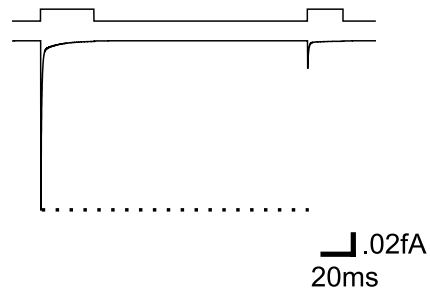

B

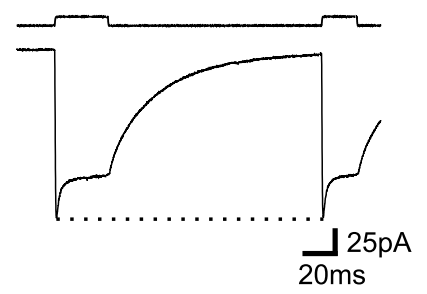

D

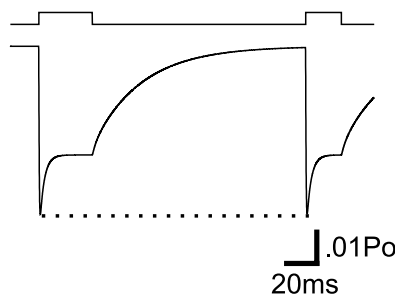

$\mathrm{F}$

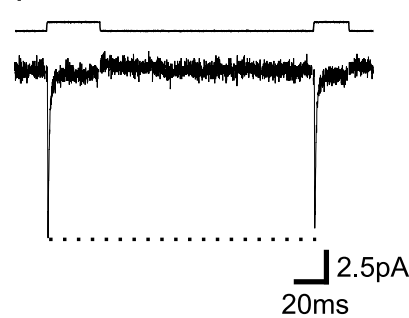

$\mathrm{H}$

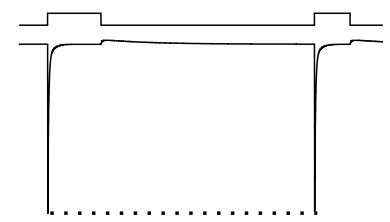

ل.02fA

Figure 7. Replacement of internal $\mathrm{K}^{+}$with $\mathrm{Na}^{+}$inhibits transporter cycling. $A$, Response of a patch to the paired application of L-glutamate (10 mM) separated by $120 \mathrm{msec}$, recorded with a NaSCN-based internal solution. $B$, Response of a different patch to the paired application of L-glutamate $(10 \mathrm{~mm})$ recorded with a NaSCN-based internal solution containing $10 \mathrm{~mm} \mathrm{~L}$-glutamate. $C$, Simulation of the response to the paired application of L-glutamate $(10 \mathrm{~mm})$ separated by $120 \mathrm{msec}$ with a NaSCNbased internal solution. $D$, Simulation response to the paired application of L-glutamate $(10 \mathrm{~mm})$ separated by $120 \mathrm{msec}$ with a NaSCN-based internal solution containing $10 \mathrm{~mm}$ L-glutamate. $E$, Response of a patch to the paired application of L-glutamate $(10 \mathrm{~mm})$ recorded without permeant anions in the internal solution (Na-gluconate-based internal solution). $F$, Response of a patch to the paired application of L-glutamate $(10 \mathrm{~mm})$ recorded with a Na-gluconate-based internal containing $10 \mathrm{~mm}$ L-glutamate. $G$, Same as $C$ but without internal permeant anions (Nagluconate-based internal solution). $H$, Same as $D$ but without permeant anions (Na-gluconate-based internal solution and $10 \mathrm{~mm}$ L-glutamate).

$(-110.2 \pm 12.6 \mathrm{pA} ; n=5)$ than those recorded with internal $\mathrm{K}^{+}$ $(206.2 \pm 21.3 \mathrm{pA} ; n=20)$. These currents rose to a peak rapidly $(340 \pm 16 \mu \mathrm{sec})$ but decayed more slowly to a steady-state level (Fig. 7A). Surprisingly, the steady-state current persisted despite the removal of L-glutamate, suggesting that in the absence of internal $\mathrm{K}^{+}$the transporter continued to visit a conducting state. Recovery of the response was very slow, because the peak response recovered by only $16 \pm 3 \%(n=5)$ after $120 \mathrm{msec}$. Indeed, for these experiments the repetition rate had to be increased from

every $5 \mathrm{sec}$ to every $15 \mathrm{sec}$ to allow the transporter current to recovery fully between pulses of glutamate. That the response does recover, albeit slowly, indicates that there is a mechanism by which the transporters can become competent to bind glutamate again, even in the absence of internal $\mathrm{K}^{+}$.

If intracellular concentrations of $\mathrm{Na}^{+}$and glutamate rise, the transporter is forced to operate in an "exchange mode" (Kanner and Bendahan, 1982; Otis and Jahr, 1998), decreasing the net influx of glutamate and $\mathrm{Na}^{+}$. When $10 \mathrm{~mm}$ L-glutamate was added to the NaSCN intracellular solution, transporter currents elicited by external glutamate had an amplitude $(-142.3 \pm 17.0 \mathrm{pA} ; n=$ 4) and rise time $(320 \pm 38 \mu \mathrm{sec})$ similar to those recorded with NaSCN alone (Fig. 7B). However, the amplitude of the steadystate response was increased dramatically $(\mathrm{SS} /$ peak ratio $=0.73 \pm$ 0.09 ), as expected if transporters are forced to enter a conducting state repeatedly. With the removal of extracellular L-glutamate this current decayed with a $\tau$ of $35.6 \pm 4.3 \mathrm{msec}$ (single exponential fit) compared with the biexponential fit $(\tau 1=1.36 \pm 0.11$ msec, $74 \% ; \tau 2=21.94 \pm 2.1 \mathrm{msec}$ ) observed with $\mathrm{K}^{+}$inside. The slow decay of this current may, in part, reflect the relatively slow unbinding of glutamate to the outside (see below). However, this decay was strongly voltage-dependent and became faster at more depolarized potentials (data not shown), indicating a voltagedependent transition in the path to unbinding. The ability of intracellular glutamate to force unbinding to the outside allowed the peak of the transporter current to recover by $96 \pm 4 \%$ in 120 $\operatorname{msec}(n=4)$.

The behavior of the stoichiometric current was analyzed under similar conditions. Application of glutamate to patches with Nagluconate inside elicited transient inward currents (Fig. 7E). As with Cs-gluconate, these responses were significantly smaller than those recorded with $\mathrm{K}^{+}$inside (peak amplitude, $-6.8 \pm 2.5 \mathrm{pA}$; $n=5$ ). In contrast to the responses recorded with $\mathrm{SCN}^{-}$, transporter currents recorded under these conditions decayed to almost zero, suggesting that internal $\mathrm{Na}^{+}$does not support cycling readily. Consistent with this hypothesis, the peak amplitude recovered by only $20 \pm 4 \%$ in $120 \mathrm{msec}$, similar to that observed with NaSCN. The addition of $10 \mathrm{~mm}$ glutamate to the $\mathrm{Na}$ gluconate solution did not change the size of the peak response to $10 \mathrm{~mm}$ external glutamate significantly (peak amplitude, $-21.2 \pm$ $12.0 \mathrm{pA} ; n=3$ ) (Fig. $7 F$ ); however, as seen for NaSCN, this manipulation accelerated the recovery from steady state such that the peak amplitude now recovered by $91 \pm 7 \%$ at $120 \mathrm{msec}$.

The model reproduces the effects of substituting internal $\mathrm{K}^{+}$ with $\mathrm{Na}^{+}$(Fig. 7C,D). In the absence of internal glutamate the model predicts that transporters will accumulate into internal $\mathrm{Na}^{+}$-bound states. As transporters collect inside, the anion current disappears unless a conducting state can be visited from the inside. The sustained anion current evoked in these conditions is reproduced well by the conducting state reached from $\mathrm{T}_{\mathrm{i}} \mathrm{Na}_{2}$, the first internal state reached in the cycle that is not bound by glutamate. The accumulation of transporters in internal states is reversible, because $\sim 20 \%$ of the current does recover after 120 msec (Fig. 8). The model can mimic this slow recovery in two ways, either by having a slow transition between $\mathrm{T}_{\mathrm{i}} \mathrm{Na}_{2}$ and $\mathrm{T}_{\mathrm{o}} \mathrm{Na}_{2}$ or by allowing internal $\mathrm{Na}^{+}$to substitute for the normally $\mathrm{K}^{+}$driven translocation. Although the present data do not distinguish between these two possibilities, the latter possibility has been depicted in the model (Fig. $2 A$ ). The addition of internal glutamate forces the transporter into an exchange mode, continually revisiting the $\mathrm{Na}^{+}$and glutamate-bound internal and external states. Because the open state attached to $\mathrm{T}_{\mathrm{o}} \mathrm{Na}_{3} \mathrm{GH}$ is occu- 
A
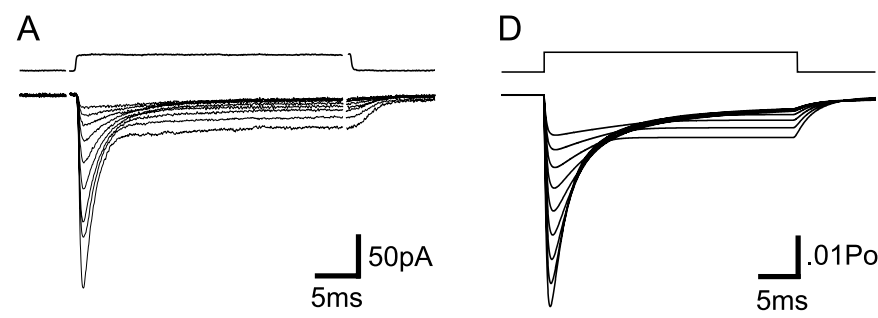

B

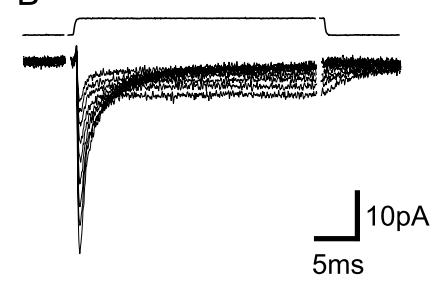

C

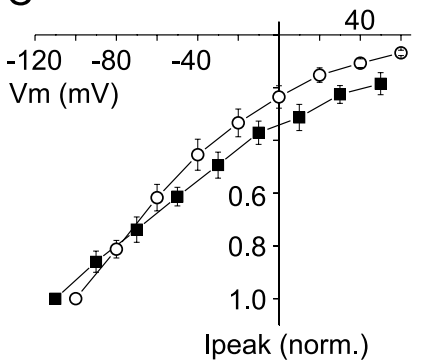

Ipeak (norm.)
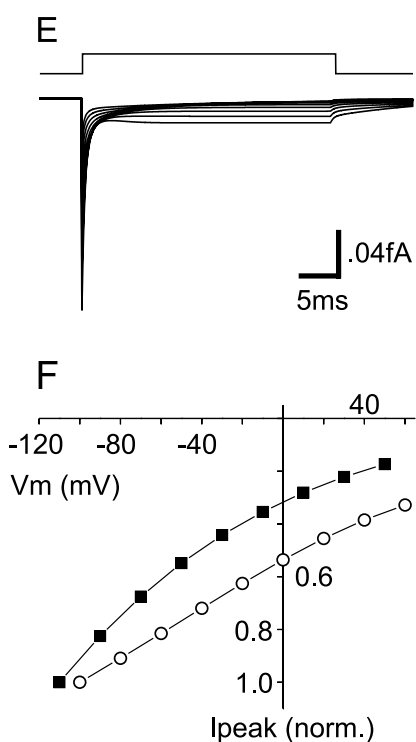

Figure 8. Voltage dependence of coupled and uncoupled GLT-1mediated transporter currents. $A$, Response of a patch to $10 \mathrm{~mm}$ L-glutamate recorded at membrane potentials between -100 and $-60 \mathrm{mV}$ (KSCN-based internal solution). $B$, Response of a patch to $10 \mathrm{~mm}$ L-glutamate recorded at membrane potentials between -110 and $-50 \mathrm{mV}$ (K-gluconate-based internal solution). $C$, Plot of the current to voltage $(I-V)$ relationship for the peak amplitude recorded in response to $10 \mathrm{~mm}$ L-glutamate in the presence (KSCN, open circles) or absence (Kgluconate, filled squares) of permeant anions. $D$, Simulation of uncoupled conductance to $10 \mathrm{~mm}$ L-glutamate recorded at membrane potentials between -100 and $-60 \mathrm{mV}$. E, Simulation of coupled current to $10 \mathrm{~mm}$ L-glutamate recorded at membrane potentials between -110 and -50 $\mathrm{mV}$. F, Simulated current to voltage $(I-V)$ relationships for the peak amplitude simulated responses in $D$ (uncoupled conductance, filled circles) and $E$ (coupled current, filled squares).

pied repeatedly in this condition, a large steady-state current is achieved. When external glutamate is withdrawn, the relatively slow glutamate unbinding rate to the outside forces the transporter to exchange a few times before glutamate unbinds at the external face. This slow relaxation is responsible for the relatively slow decay of the anion current at the end of the glutamate pulse. The voltage dependence of this decay is the result of the voltage dependence of the binding and unbinding of the third $\mathrm{Na}^{+}$, which precedes external glutamate unbinding.

The stoichiometric currents recorded with Na-gluconate-based internal solutions can be replicated by this model without further modifications (Fig. $7 G, H$ ). In the absence of internal glutamate the transporters accumulate in internal states, and no steady-state current is seen, reflecting a lack of cycling through the $\mathrm{K}^{+}$ counter-transport transition. In the presence of internal glutamate, after an initial transient net influx, again the steady state is nonexistent as cycling is reduced to zero through the $\mathrm{K}^{+}$countertransport transition.

\section{Voltage dependence of transport}

The uptake of glutamate by GLT-1 is strongly voltage-dependent (Wadiche et al., 1995b; Levy et al., 1998). We examined the voltage dependence of GLT-1 transporter currents by applying 10 mM L-glutamate to patches held at range of potentials between -100 and $50 \mathrm{mV}$. The current to voltage $(I-V)$ relationship of the peak of the response exhibited prominent inward rectification, and transporter currents did not reverse at potentials as positive as $50 \mathrm{mV}$ (Fig. 8A,C). A similar rectification of peak currents was observed with recordings in the absence of permeant anions (K-gluconate internal solution) (Fig. 8B,C). The model accounts for the voltage dependence of transport by assigning voltage dependence to the first and third $\mathrm{Na}^{+}$binding step to the external face of the transporter, the unbinding step of the first $\mathrm{Na}^{+}$after translocation $\left(\mathrm{T}_{\mathrm{i}} \mathrm{Na}_{3} \mathrm{GH}\right.$ to $\left.\mathrm{T}_{\mathrm{i}} \mathrm{Na}_{2} \mathrm{GH}\right)$, and the $\mathrm{K}^{+}$-dependent translocation (A. Tzingounis, personal communication). In addition, the voltage dependencies of the internal $\mathrm{Na}^{+}$binding step and the $\mathrm{K}^{+}$-dependent translocation are asymmetrical. These asymmetries are required to mimic the kinetics of the currents across the range of holding potentials that were tested.

In the previous figures anion currents are simulated as open probabilities $\left(P_{\mathrm{o}}\right)$. However, when different holding potentials are compared, the $P_{\mathrm{o}}$ should be scaled according to the electrochemical gradient and the voltage dependence of the anion conductances. Unfortunately, we have not been able to measure the voltage dependence of the anion conductances independently of $P_{\mathrm{o}}$. We have measured the $I-V$ relationship of the substrateindependent anion leak current, as described below. If we assume that the voltage dependence of the conductance states activated by glutamate is the same as that of the leak current, we can scale the simulated $P_{\mathrm{o}}$ traces by using the $I-V$ relationship obtained for the leak current. When this scaling is performed, however, the simulated voltage dependence of glutamate-evoked anion currents is far too great, suggesting that the voltage dependence of the leak current is not the same as that for glutamate-evoked conductances. The simulations (Fig. $8 D, F$ ), therefore, are presented as the unaltered $P_{\mathrm{o}}$.

\section{Pharmacological inhibition of transporter currents}

EAAT2 transporters are inhibited by the nontransported antagonist dihydrokainate (DHK) with a $K_{\mathrm{i}}$ of between 24 and $79 \mu \mathrm{M}$ (Arriza et al., 1994; Shimamoto et al., 1998), an affinity 100-fold greater than that for other glutamate transporters. In the presence of permeant anions ( $\mathrm{SCN}^{-}$internal) $\mathrm{DHK}$ alone produced an outward shift in the holding current (Fig. 9A), consistent with observations made in patches from astrocytes (Bergles and Jahr, 1997) and from HEK cells expressing EAAT2 (Otis and Kavanaugh, 2000). This outward shift suggests that there is a leak of anions through the transporters that is maintained in the absence of glutamate and blocked by DHK. The voltage dependence of the DHK-induced responses was the inverse of that observed for L-glutamate (Fig. 9B), as expected if these responses were mediated by an inhibition of a resting anion current. With the removal of DHK the current returned to baseline with a $\tau$ of $23.2 \pm 2.8$ msec ( $n=4$; single exponential fit). This decay provides an estimate for the unbinding rate of DHK, if it is assumed that the conductance opens without delay after the unbinding of DHK. The application of TBOA $(300 \mu \mathrm{M})$, a nontransported antagonist that has an $\sim 10$-fold higher affinity for EAAT2 $\left(K_{\mathrm{i}}=5.7 \mu \mathrm{M}\right.$; Shimamoto et al., 1998), produced a similar maximal shift in the holding current but decayed with a $\tau$ of $247.2 \pm 20.4 \mathrm{msec}(n=4$; single exponential fit) with removal, indicating that TBOA un- 
Figure 9. Block of anion leak current by nontransported GLT-1 antagonists. $A$, The application of dihydrokainate (DHK; $300 \mu \mathrm{M})$ or D,L-threo- $\beta$-benzyloxyaspartate $(T B O A ; 300 \mu \mathrm{M})$ elicited outward shifts in the holding current in patches recorded with permeant anions in the internal solution (KSCN-based internal solution). The response to the same patch to $10 \mathrm{~mm} \mathrm{~L}$-glutamate is shown by the bottom trace. The values for the vertical scale bar are $20 \mathrm{pA}$ (top traces) and $60 \mathrm{pA}$ (bottom trace). B, Voltage dependence of

the peak amplitudes of responses to either $300 \mu \mathrm{M}$ DHK ( filled circles; error bars within symbols) or 10 mM L-glutamate ( filled squares). Inset, responses to DHK at potentials between -100 and $60 \mathrm{mV}$. Calibration: $10 \mathrm{msec}, 20 \mathrm{pA}$. $C$, Simulations of responses to DHK $\left(\right.$ binding rate, $3 \times 10^{6}$ per $\mathrm{m} / \mathrm{sec}$; unbinding rate, $165 / \mathrm{sec}$ ) and to TBOA (binding rate, $3 \times 10^{6} \mathrm{per} \mathrm{M} / \mathrm{sec}$; unbinding rate, $6 / \mathrm{sec}$ ).
A

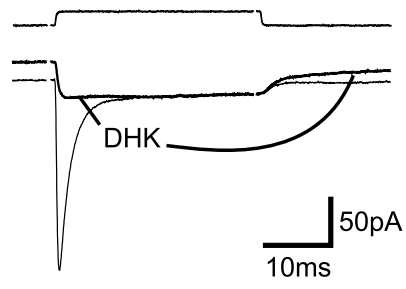

C

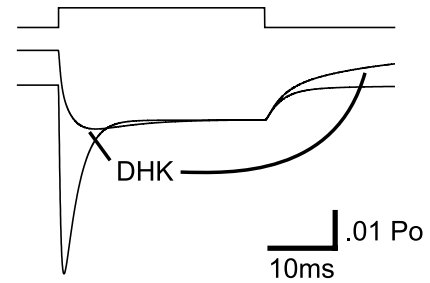

A

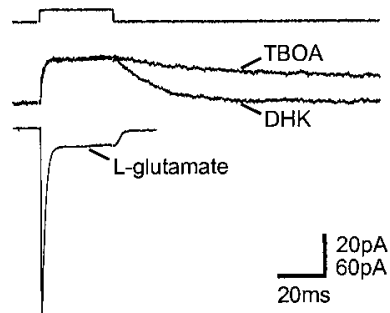

B

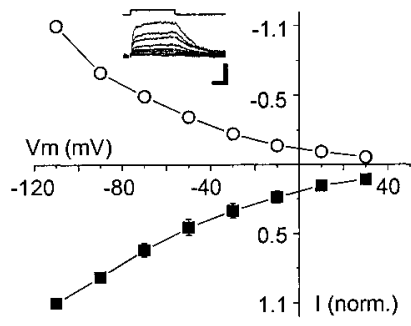

C

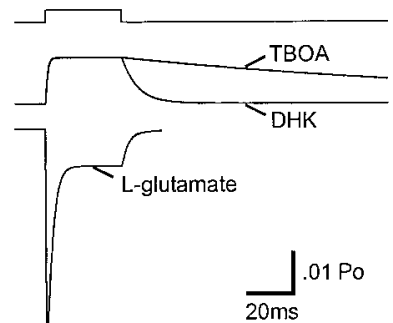

Figure 10. Kinetics of inhibition of GLT-1 transporters by DHK. A, Response of a patch to either $10 \mathrm{~mm}$ L-glutamate alone (bottom trace, thin line) or $10 \mathrm{~mm}$ L-glutamate plus $300 \mu \mathrm{M}$ DHK (top trace, thick line); for the latter response the patches were stepped from a solution with $300 \mu \mathrm{M}$ DHK to one containing $10 \mathrm{mM}$ L-glutamate plus $300 \mu \mathrm{M}$ DHK. $B$, Responses recorded in the absence of permeant anions in the internal solution (K-gluconate internal solution) as in $A$. $C$, Simulations of uncoupled conductance illustrating the effect of DHK $(300 \mu \mathrm{M})$ on the response of GLT-1 to $10 \mathrm{~mm}$ L-glutamate. $D$, Simulations of coupled current illustrating the effect of DHK.

binds much more slowly than DHK from GLT-1 transporters (Fig. 9A). It was possible to model these decays by setting the unbinding rate of $\mathrm{DHK}$ as $165 / \mathrm{sec}$ and the unbinding rate of TBOA as 6/sec (Fig. 9C).

We examined the kinetics of inhibition of GLT-1 by DHK by measuring the effect of $300 \mu \mathrm{M}$ DHK on the response to a saturating dose of L-glutamate $(10 \mathrm{mM})$. As expected from the results above, DHK alone produced an outward shift in the holding current. In addition, DHK inhibited the peak, but not the steadystate current, in response to L-glutamate (Fig. 10 $\mathrm{A}$ ); presumably, 10 mM glutamate is sufficient to overwhelm this competitive antagonist at steady state despite a high occupancy by DHK in the absence of glutamate. In the absence of permeant anions (Kgluconate internal) DHK $(300 \mu \mathrm{M})$ also inhibited the peak of the response to L-glutamate $(10 \mathrm{~mm})$ (Fig. $10 B)$. However, as expected because of the absence of permeant anions and thus the leak current, DHK produced no outward shift in the holding current.

The major features of inhibition of both anion and stoichiometric currents by DHK were reproduced by the model (Fig.
$10 C, D$ ). The predicted microscopic affinity for DHK is $55 \mu \mathrm{M}$ (on rate $=3 \times 10^{6} \mathrm{per} \mathrm{M} / \mathrm{sec}$; off rate $\left.=165 / \mathrm{sec}\right)$, a value in the range measured experimentally for EAAT2 [Arriza et al. (1994), $K_{\mathrm{i}}=$ $23 \mu \mathrm{M}$; Shimamoto et al. (1998), $\left.\mathrm{IC}_{50}=196 \mu \mathrm{M}\right]$.

\section{Agonist-dependent changes in kinetics}

Different excitatory amino acids have been shown to elicit transporter currents with dramatically different kinetics (Bergles and Jahr, 1997; Wadiche and Kavanaugh, 1998), in part because of the different affinities of the transporters for different agonists (Arriza et al., 1994). In particular, transporter currents in outside-out patches recorded from oocytes expressing EAAT1 transporters (Wadiche and Kavanaugh, 1998), from astrocytes (Bergles and Jahr, 1997), and from Bergmann glial cells (Bergles et al., 1997) exhibited much slower kinetics in response to aspartate than to glutamate. Unexpectedly, the kinetics of GLT-1 in response to L-glutamate and D-aspartate were very similar (data not shown), and the amplitudes of the steady-state currents were not significantly different (paired $t$ test) (L-glutamate, $-19.4 \pm 3.3 \mathrm{pA}$; D-aspartate, $-19.6 \pm 3.7 \mathrm{pA} ; n=15)$. However, with permeant anions the peak amplitude of D-aspartate currents was $66 \pm 1 \%$ $(n=15)$ of L-glutamate, resulting in a significantly larger SS/peak ratio (D-aspartate, $0.22 \pm 0.02$; L-glutamate, $0.12 \pm 0.01 ; n=15$ ). In addition, D-aspartate-evoked currents decayed more slowly at the end of the pulse. Coupled transporter currents recorded with internal K-gluconate exhibited the same features; the peak amplitude of responses to D-aspartate was $79 \pm 3 \%(n=12)$ of the L-glutamate response (data not shown), although the steady-state amplitudes were not significantly different (paired $t$ test) (Lglutamate, $-3.5 \pm 0.5 \mathrm{pA}$; D-aspartate, $-3.5 \pm 0.4 \mathrm{pA} ; n=12$ ). These differences can be simulated, at least qualitatively, if the binding and unbinding rates of $\mathrm{D}$-aspartate are slowed relative to L-glutamate, the forward translocation rate is decreased by $35 \%$, and the opening rate of the conductance from the fully bound state $\left(\mathrm{T}_{\mathrm{o}} \mathrm{Na}_{3} \mathrm{GH}\right)$ is approximately halved. The slowed translocation rate is in line with the observed lower flux rate of D-aspartate than L-glutamate through EAAT2 $\left(I_{\max } \mathrm{D}\right.$-aspartate $/ I_{\max }$ L-glutamate $=0.84$; Arriza et al., 1994). However, the lack of difference between steady-state stoichiometric currents indicates that in these conditions the uptake of the two substrates should be similar. Indeed, the model predicts that the cycling rate achieved with an application of $10 \mathrm{~mm}$ D-aspartate is also 42/sec, indicating that for $\mathrm{D}$-aspartate transport the $\mathrm{K}^{+}$counter-transport transition is similarly rate-limiting.

\section{DISCUSSION}

The translocation of glutamate by the $\mathrm{Na}^{+}$-dependent glutamate transporters is associated with net movement of positive charge 
through the membrane field. This unbalanced stoichiometry results from the movement of $3 \mathrm{Na}^{+}, 1 \mathrm{H}^{+}$into the cell with each negatively charged molecule of glutamate and only $1 \mathrm{~K}^{+}$out (Zerangue and Kavanaugh, 1996; Levy et al., 1998). In addition to this movement of cations essential for glutamate translocation and transporter cycling, glutamate transporters also allow anions to flow across the membrane (Fairman et al., 1995; Wadiche et al., 1995a; Eliasof and Jahr, 1996). In this study we used a heterologous expression system (Dunlop et al., 1999) to create a high density of GLT-1 transporters in the plasma membrane so that the kinetic properties of both the stoichiometric and anion currents associated with glutamate uptake could be recorded in outside-out patches. These studies revealed that the kinetics of the anion currents are slower than stoichiometric currents but that anions do not alter appreciably the recovery rate or the efficiency of GLT-1 transporters. We developed a chemical-kinetic model that mimics the behavior of GLT-1, in which the anion conductance is associated with multiple states in the cycle and the rate-limiting transition occurs during the counter-transport of $\mathrm{K}^{+}$(Kanner and Sharon, 1978; Kanner and Bendahan, 1982).

\section{Relationship between stoichiometric and anion currents}

Although transporter currents recorded with and without permeant anions had similar waveforms, the stoichiometric current rose faster and decayed more rapidly from the peak than the anion current, as shown previously for astrocyte transporters (Bergles and Jahr, 1997), for EAAC1 (Grewer et al., 2000; Watzke et al., 2001), and for Purkinje cell transporters (Auger and Attwell, 2000; Wadiche and Jahr, 2001). However, the slower kinetics of the anion-potentiated transporter currents were not translated into a slower overall paired pulse recovery rate of GLT-1, suggesting that states in the transport cycle are occupied for similar periods whether or not permeable anions are present. The slower time course of the anion currents suggests that conducting states are reached, and can be revisited, subsequent to the movement of coupled charges through the membrane field. More dramatic differences in the kinetics of anion and stoichiometric currents were observed when internal $\mathrm{K}^{+}$was substituted with $\mathrm{Na}^{+}$. With permeant anions inside (NaSCN-based internal solution), the current remained active long after glutamate removal, whereas in the absence of permeant anions (Na-gluconate-based internal solution) the stoichiometric current decayed to zero. When $\mathrm{Na}^{+}$is the only internal cation, external glutamate causes transporters to accumulate in $\mathrm{Na}^{+}$-bound internal states that conduct anions. The lack of a steady-state component of the stoichiometric current indicates that cycling occurs only very slowly in this condition. Similarly, internal $\mathrm{Cs}^{+}$substitution also dramatically slowed cycling, indicating that $\mathrm{Cs}^{+}$is inefficient at supporting counter-transport. It is possible that anions also slow transitions between some states in the transport cycle, as suggested by Auger and Attwell (2000) for Purkinje cell glutamate transporters. However, such an effect would have to be small compared with the rate-limiting $\mathrm{K}^{+}$counter-transport step, because anions affect neither paired pulse recovery (Fig. 4) nor glutamate flux in steady-state conditions (Wadiche et al., 1995a).

\section{Efficiency of transport by GLT-1}

An important parameter of transport is the probability that the binding of a molecule of substrate to the external face of the transporter leads to release of a molecule of substrate into the cytoplasm (i.e., transport) rather than back into the extra- cellular space. If substantial extracellular unbinding occurs in physiological conditions, glutamate will have the opportunity to bind to receptors long after release, although transporters still could lower the concentration of glutamate in the extracellular space rapidly and slow diffusion through buffering (Rusakov and Kullmann, 1998; Diamond, 2001) (but see Barbour, 2001). We have estimated the efficiency of this transporter by simulating a very short $(1 \mu \mathrm{sec})$ application of glutamate and measuring the net flux through the unbinding transitions to either the internal and external faces. The ratio of unbinding to the inside to the sum of unbinding on both sides provides a measure of the efficiency of the transporter. Under the conditions used for the majority of the experiments in this study ( 0 glutamate, $0 \mathrm{Na}^{+}$internal), the predicted efficiency of GLT-1 is $65 \%$. This value is particularly sensitive to the unbinding rate of glutamate to the outside, a rate that unfortunately is not well defined. The dose-response relationship (Fig. 1), for instance, can be simulated reasonably well with off rates ranging from 250 to $1000 / \mathrm{sec}$; however, the estimate of efficiency changes from 79 to $48 \%$, respectively, over this range. If we use an unbinding rate of $500 / \mathrm{sec}$, changing the internal composition to one that may be more representative of astrocyte cytoplasm (10 $\mathrm{mm} \mathrm{Na}{ }^{+}, 50 \mu \mathrm{M}$ glutamate) had little effect on efficiency $(64 \%)$, whereas decreasing the holding potential from -90 to $-60 \mathrm{mV}$ lowered the efficiency to $50 \%$. Increasing internal glutamate to $10 \mathrm{~mm}$ further decreased the efficiency to $44 \%$. Under these conditions efficiency becomes the probability that there will be a net flux of one glutamate molecule from the outside to the inside per cycle; when glutamate and $\mathrm{Na}^{+}$are present internally, the translocation of one molecule of glutamate from outside to inside can be followed by the reverse translocation of glutamate from the cytoplasm to the extracellular fluid, thereby decreasing efficiency. These results indicate that many transporters function as buffers only, rather than as unidirectional transporters that force the net accumulation of glutamate.

\section{Comparison of GLT-1 to astroglial transporter currents}

GLT-1 (EAAT2) is the predominant glutamate transporter in the mammalian brain (Rothstein et al., 1994; Lehre et al., 1995) and is essential for maintaining a low ambient level of glutamate (Rothstein et al., 1996; Tanaka et al., 1997). This transporter is expressed at a high density in astrocyte membranes (Lehre et al., 1995), a density sufficient to allow electrogenic transporter currents to be resolved in outside-out patches from these cells in acute brain slices (Bergles and Jahr, 1997, 1998). GLT-1 transporter currents evoked by L-glutamate exhibited many of the same characteristics as those recorded in patches from astrocytes, including a rapid rise to a peak, a decay to a steady-state level in the continued presence of L-glutamate that was $\sim 10 \%$ of the peak amplitude, and an $\mathrm{EC}_{50}$ at steady state that was $\sim 13 \mu \mathrm{M}$. This is in close agreement with the equilibrium $K_{\mathrm{m}}$ measurements made from GLT-1 expressed in Chinese hamster ovary cells $(16.5 \mu \mathrm{M}$; Levy et al., 1998). In addition, both GLT-1 and astrocyte transporter currents were $\sim 10$-fold larger when recorded in the presence of $\mathrm{SCN}^{-}$in the internal solution, consistent with the high permeability of these transporters to chaotropic anions (Wadiche et al., 1995a). GLT-1 transporters also exhibited a substrateindependent leak of anions that could be blocked by the nontransported antagonists DHK and TBOA. However, GLT-1 transporter currents exhibited a slower rise time, a slower decay time in the continued presence of L-glutamate, and a prominent biexponential decay after the removal of L-glutamate. This trend toward slower kinetics differs from that observed for the EAAT2 
transporter recorded in patches from HEK cells, which had somewhat faster initial kinetics than those observed here (Otis and Kavanaugh, 2000). These differences are somewhat surprising given the high sequence homology between EAAT2 and GLT-1 (Kanner, 1993; Arriza et al., 1994). However, a similar biexponential decay after the removal of glutamate was reported for EAAT2 transporters (Otis and Kavanaugh, 2000).

A dramatic difference between GLT-1 and astrocyte transporter currents was observed in the kinetics of the response to D-aspartate (Fig. 7D) (Bergles and Jahr, 1997). D-Aspartate-evoked transporter currents from astrocytes exhibited a prominent steady-state component that was not observed with GLT-1 (SS/peak ratio: GLT-1, $0.22 \pm 0.02$; astrocyte, $0.52 \pm 0.15)$. This difference may reflect the presence of GLAST glutamate transporters that also are expressed in hippocampal astrocytes (Rothstein et al., 1994; Lehre et al., 1995), because transporter currents mediated by EAAT1, the human homolog of GLAST, exhibit an enhanced steady-state current in response to D-aspartate (Wadiche and Kavanaugh, 1998) and transporter currents recorded from Bergmann glial cells, which express a high density of GLAST transporters (Rothstein et al., 1994; Lehre et al., 1995), exhibit a large steady-state current in response to L-aspartate (Bergles et al., 1997). These observations are consistent with the complete inhibition of the peak amplitude of GLT-1 transporter currents by DHK (Fig. 10), an antagonist with a $>100$-fold higher affinity for EAAT2 than for EAAT1 transporters (Arriza et al., 1994), but only a partial inhibition of the peak amplitude of astrocyte transporter currents [Bergles and Jahr (1997), their Fig. 6E].

The ability to record both stoichiometric charge movement and anion permeation mediated by GLT-1 has allowed for the creation of a kinetic model of transport that reproduces both coupled and uncoupled currents measured experimentally. The model has been used to estimate the efficiency of glutamate transport and rates of cycling in a variety of conditions those parameters of transport that have not been amenable to direct experimental determination. These characteristics of transport may be critical in determining the activation of glutamate receptors both within and surrounding the synaptic cleft after exocytotic release and during pathological conditions such as ischemia.

\section{REFERENCES}

Arriza JL, Fairman WA, Wadiche JI, Murdoch GH, Kavanaugh MP, Amara SG (1994) Functional comparisons of three glutamate transporter subtypes cloned from human motor cortex. J Neurosci 14:5559-5569.

Auger C, Attwell D (2000) Fast removal of synaptic glutamate by postsynaptic transporters. Neuron 28:547-558.

Barbour B (2001) An evaluation of synapse independence. J Neurosci 21:7969-7984.

Barbour B, Attwell D (1991) Electrogenic uptake of glutamate and aspartate into glial cells isolated from the salamander (Ambystoma) retina. J Physiol (Lond) 436:169-193.

Bergles DE, Jahr CE (1997) Synaptic activation of glutamate transporters in hippocampal astrocytes. Neuron 19:1297-1308.

Bergles DE, Jahr CE (1998) Glial contribution to glutamate uptake at Schaffer collateral $\rightarrow$ commissural synapses in the hippocampus. J Neurosci 18:7709-7716.

Bergles DE, Dzubay J, Jahr CE (1997) Glutamate transporter currents in Bergmann glial cells follow the time course of extrasynaptic glutamate. Proc Natl Acad Sci USA 94:14821-14825.

Chatton JY, Marquet P, Magistretti PJ (2000) A quantitative analysis of L-glutamate-regulated $\mathrm{Na}^{+}$dynamics in mouse cortical astrocytes: implications for cellular bioenergetics. Eur J Neurosci 12:3843-3853.

Diamond JS (2001) Neuronal glutamate transporters limit activation of NMDA receptors by neurotransmitter spillover on CA1 pyramidal cells. J Neurosci 21:8328-8338.

Dunlop J, Lou Z, McIlvain HB (1999) Steroid hormone-inducible expression of the GLT-1 subtype of high-affinity L-glutamate transporter in human embryonic kidney cells. Biochem Biophys Res Commun 265:101-105.
Eckstein-Ludwig U, Rettinger J, Vasilets LA, Schwarz W (1998) Voltage-dependent inhibition of the $\mathrm{Na}^{+} / \mathrm{K}^{+}$pump by tetraethylammonium. Biochim Biophys Acta 1372:289-300.

Eliasof S, Jahr CE (1996) Retinal glial cell glutamate transporter is coupled to an anionic conductance. Proc Natl Acad Sci USA 93:4153-4158.

Fairman WA, Vandenberg RJ, Arriza JL, Kavanaugh MP, Amara SG (1995) An excitatory amino-acid transporter with properties of a ligand-gated chloride channel. Nature 375:599-603.

Grewer C, Watzke N, Wiessner M, Rauen T (2000) Glutamate translocation of the neuronal glutamate transporter EAAC1 occurs within milliseconds. Proc Natl Acad Sci USA 97:9706-9711.

Kanner BI (1993) Glutamate transporters from brain: a novel neurotransmitter transporter family. FEBS Lett 352:95-99.

Kanner BI, Bendahan A (1982) Binding order of substrates to the sodium and potassium ion coupled L-glutamic acid transporter from rat brain. Biochemistry 21:6327-6330.

Kanner BI, Sharon I (1978) Active transport of L-glutamate by membrane vesicles isolated from rat brain. Biochemistry 17:3949-3953.

Kavanaugh MP (1998) Neurotransmitter transport: models in flux. Proc Natl Acad Sci USA 95:12737-12738.

Larsson HP, Picaud SA, Werblin FS, Lecar H (1996) Noise analysis of the glutamate-activated current in photoreceptors. Biophys $\mathbf{J}$ 70:733-742.

Läuger P (1991) Electrogenic ion pumps. Sunderland, MA: Sinauer.

Lehre KP, Levy LM, Ottersen OP, Storm-Mathisen J, Danbolt NC (1995) Differential expression of two glial glutamate transporters in the rat brain: quantitative and immunocytochemical observations. J Neurosci 15:1835-1853.

Levy LM, Warr O, Attwell D (1998) Stoichiometry of the glial glutamate transporter GLT-1 expressed inducibly in a Chinese hamster ovary cell line selected for low endogenous $\mathrm{Na}^{+}$-dependent glutamate uptake. J Neurosci 18:9620-9628.

Mennerick S, Shen W, Xu W, Benz A, Tanaka K, Shimamoto K, Isenberg KE, Krause JE, Zorumski CF (1999) Substrate turnover by transporters curtails synaptic glutamate transients. J Neurosci 19:9242-9251.

Omay HS, Schwarz W (1992) Voltage-dependent stimulation of $\mathrm{Na}^{+} / \mathrm{K}^{+}$pump current by external cations: selectivity of different $\mathrm{K}^{+}$ congeners. Biochim Biophys Acta 1104:167-173.

Otis TS, Jahr CE (1998) Anion currents and predicted glutamate flux through a neuronal glutamate transporter. J Neurosci 18:7099-7110.

Otis TS, Kavanaugh MP (2000) Isolation of current components and partial reaction cycles in the glial glutamate transporter EAAT2. J Neurosci 20:2749-2757.

Otis TS, Kavanaugh MP, Jahr CE (1997) Postsynaptic glutamate transport at the climbing fiber-Purkinje cell synapse. Science 277:1515-1518.

Rothstein JD, Martin L, Levey AI, Dykes-Hoberg M, Jin L, Wu D, Nash N, Kuncl RW (1994) Localization of neuronal and glial glutamate transporters. Neuron 13:713-725.

Rothstein JD, Dykes-Hoberg M, Pardo CA, Bristol LA, Jin L, Kuncl RW, Kanai Y, Hediger MA, Wang Y, Schielke JP, Welty DF (1996) Knock-out of glutamate transporters reveals a major role for astroglial transport in excitotoxicity and clearance of glutamate. Neuron 16:675-686.

Rusakov DA, Kullmann DM (1998) Extrasynaptic glutamate diffusion in the hippocampus: ultrastructural constraints, uptake, and receptor activation. J Neurosci 18:3158-3170.

Shimamoto K, Lebrun B, Yasuda-Kamatani Y, Sakaitani M, Shigeri Y, Yumoto N, Nakajima T (1998) DL-Threo- $\beta$-benzyloxyaspartate, a potent blocker of excitatory amino acid transporters. Mol Pharmacol 53:195-201

Sonders MS, Amara SG (1996) Channels in transporters. Curr Opin Neurobiol 6:294-302.

Tanaka K, Watase K, Manabe T, Yamada K, Watanabe M, Takahashi K, Iwama H, Nishikawa T, Ichihara N, Kikuchi T, Okuyama S, Kawashima N, Hori S, Takimoto M, Wada K (1997) Epilepsy and exacerbation of brain injury in mice lacking the glutamate transporter GLT-1. Science 276:1699-1702.

Tong G, Jahr CE (1994) Multivesicular release from excitatory synapses of cultured hippocampal neurons. Neuron 12:51-59.

Wadiche JI, Jahr CE (2001) Multivesicular release at climbing fiberPurkinje cell synapses. Neuron 32:301-313.

Wadiche JI, Kavanaugh MP (1998) Macroscopic and microscopic properties of a cloned glutamate transporter/chloride channel. J Neurosci 18:7650-7661.

Wadiche JI, Amara SG, Kavanaugh MP (1995a) Ion fluxes associated with excitatory amino acid transport. Neuron 15:721-728.

Wadiche JI, Arriza JL, Amara SG, Kavanaugh MP (1995b) Kinetics of a human glutamate transporter. Neuron 14:1019-1027.

Watzke N, Bamberg E, Grewer C (2001) Early intermediates in the transport cycle of the neuronal excitatory amino acid carrier EAAC1. J Gen Physiol 117:547-562.

Zerangue N, Kavanaugh MP (1996) Flux coupling in a neuronal glutamate transporter. Nature 383:634-637. 